\title{
SIMPLE DESIGN PROCEDURE FOR HIGH-POWER THREE- PHASE INVERTERS OPERATING IN PWM AND SIX-STEP MODES
}

\section{Ahmed AbdEl-malek AbdEl-hafez}

Lecturer in Electrical department, faculty of engineering, Assiut University P.O. 71561, Tel: +2 088 2411038, e-mail:Elhafez@aun.edu.eg

(Received June 7, 2010 Accepted December 16, 2010)

This paper proposes simple analytical expressions for RMS, peak, and average currents in three-phase DC/AC inverter operating under different operating conditions. The results were validated by rigorous simulation.

\section{1- INTRODUCTION}

The devices/magnetic components in a power electronic circuit are usually dimensioned for worst operating conditions. The conduction losses of a device modelled during on-state as a voltage source $\mathrm{V}_{\text {on }}$ in series with a resistor $\mathrm{r}_{\mathrm{on}}$ are given by [1, 4-7],

$$
\mathrm{P}_{\text {avg_cond }}=\mathrm{V}_{\text {on }} \mathrm{I}_{\mathrm{DC}}+\mathrm{r}_{\text {on }} \mathrm{I}_{\mathrm{RMS}}^{2}
$$

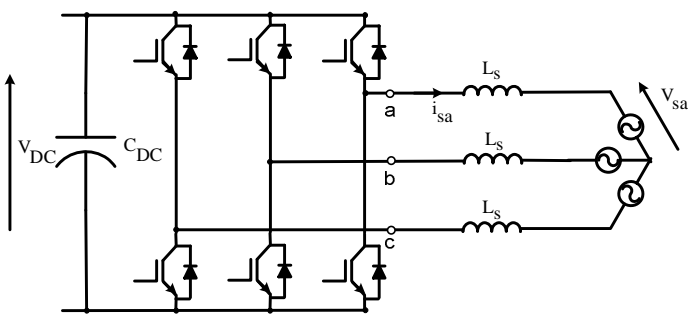

Fig. 1 Three-phase inverter supplying a rotating load

Diodes develop switching losses, due to stored charge in semiconductors. However, these losses are usually ignored, as fast recovery diodes are generally utilized in inverter circuits [7]. The turn on $\mathrm{e}_{\mathrm{on}}$ and turn off $\mathrm{e}_{\text {off }}$ energies of typical switches are usually approximated as a linear function in switch current [4-7]. Therefore, switching losses of a switch are given by,

$$
\mathrm{P}_{\text {avg_sw }}=\frac{1}{\mathrm{~T}_{\mathrm{s}}} \int_{0}^{\mathrm{T}_{\mathrm{S}}} \frac{\left(\mathrm{e}_{\mathrm{on}}+\mathrm{e}_{\text {on }}\right)}{\mathrm{T}_{\mathrm{s}}} \mathrm{dt}=\frac{\mathrm{I}_{\mathrm{DC}}\left(\mathrm{k}_{\text {on }}+\mathrm{k}_{\text {off }}\right)}{\mathrm{T}_{\mathrm{s}}}
$$

Equations (1)-(2) reflects the significance of RMS, average and peak currents in calculating the losses and hence dimensioning solid-state devices, heat sinks and magnetic components.

RMS and average currents generally computed through computer aidedanalysis [7-9]. For example, in [9] computer aided method based on Fourier series technique was used for calculating the RMS and average currents of voltage source inverters. Another computer aided analysis, based on the relation between the line 
current, switch and diode currents, is described in [7]. These techniques in general are complicated, time consuming and unreliable [7-10]. Moreover, these methods are not useful in highlighting the prominent parameters that affect the RMS, average and peak currents. Furthermore, these techniques have considerable errors, which reduce their reliability [7-10]

This paper proposes simple analytical expressions of RMS, peak, and average currents in three-phase, DC/AC inverter shown in Fig. 1. These expressions underline the parameters that affect the values of RMS, average and peak currents. Moreover, they are applicable for autonomous inverter operation with different load levels/power factors, which far as we know was not investigated before [4-9]. Furthermore, the obtained expressions are not limited on PWM mode, but they are extended to six-step mode as well. This mode is preferred option for high power applications.

The procedure for deriving expression of RMS, peak and average currents in this paper is: firstly, operation modes are divided into two types: PWM and square wave. For each mode, the following currents are derived: RMS, average, and peak. he per-phase equivalent circuit of the fundamental components of inverter output voltage, current and the load voltage is shown in Fig. 2. The relations between the voltages and current shown in Fig. 2 are illustrated in the Phasor diagram, Fig. 3.

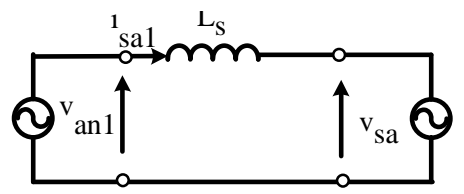

Fig. 2 Per-phase equivalent circuit of the fundamental components of the inverter output voltage, current and load voltage

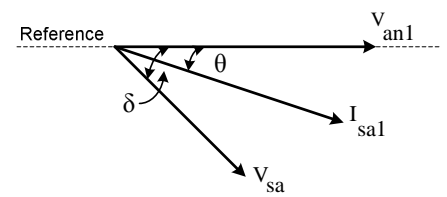

Fig. 3 Phasor diagram of the inverter output voltage, current and load voltage

\section{2- PWM}

1) RMS currents: The switch RMS current is obtained by,

$$
\mathrm{I}_{\mathrm{q}, \mathrm{RMS}}=\left(\frac{1}{\mathrm{~T}_{\mathrm{i}}} \int_{0}^{\mathrm{T}} \frac{1}{\mathrm{~T}_{\mathrm{s}}} \int_{\lambda}^{\lambda+\mathrm{T}_{\mathrm{s}_{\mathrm{q}}} 2 \mathrm{~d} \lambda \mathrm{dt}}\right)^{\frac{1}{2}}
$$

The switch current $i_{q}$ normally has a train of pulses with variable widths. Therefore to calculate the switch RMS current correctly, the RMS value should be estimated for each pulse individually, after that squaring the pulse RMS value and taking the square root of the sum of these squares gives the switch RMS current. This appears to be fairly complicated process. The problem can, however, be simplified by assuming sufficiently high switching frequency. According to that assumption, the switch and diode RMS current are derived through double integral, the inner one accounts for the switching cycle, whereas the outer stands for the line cycle. 


$$
\frac{1}{\mathrm{~T}_{\mathrm{S}}} \int_{\lambda}^{\lambda+\mathrm{T}_{\mathrm{S}}} \mathrm{i}_{\mathrm{q}}^{2} \mathrm{~d} \lambda=\left\langle\mathrm{i}_{\mathrm{q}}(\mathrm{t})\right\rangle^{2} \mathrm{~d}(\mathrm{t})
$$

Integrating switch current square over a switching cycle resembles averaging over the switching cycle. The inverter output current, Fig. 1, is assumed sinusoidal during PWM operation [10].

The switch average current over a switching cycle is identical to the inverter AC line current

$$
\left\langle\mathrm{i}_{\mathrm{q}}(\mathrm{t})\right\rangle=\mathrm{i}_{\mathrm{sa} 1}=\hat{\mathrm{I}}_{\mathrm{sa} 1} \sin (\omega \mathrm{t}-\theta)
$$

In voltage source inverter, a simple derivation yields the switch duty ratio in terms of the modulation function $[5,6,10]$.

$$
\mathrm{d}(\mathrm{t})=\frac{1+\mathrm{m}(\mathrm{t})}{2}=\frac{1+\mathrm{M} \sin (\omega \mathrm{t})}{2}
$$

In H-bridge inverter, Fig. 1, a switch/diode in switch-diode combination conducts only during half cycle of phase current. For example, the switch in the top switch-diode pair in phase a conducts during the positive half cycle of phase a current, whereas the diode in this pair conducts during the negative half cycle of the current. Substituting (5)-(6) into (3)

$$
\mathrm{I}_{\mathrm{q}, \mathrm{RMS}}=\left(\frac{1}{2 \pi} \int_{\theta}^{\theta+\pi} \frac{(1-\mathrm{M} \sin (\omega \mathrm{t}))}{2}\left(\hat{\mathrm{I}}_{\mathrm{sa}} \sin (\omega \mathrm{t}-\theta)\right)^{2} \mathrm{~d} \omega \mathrm{t}\right)^{1 / 2}
$$

Using the following two-trigonometry in (7),

$$
\begin{gathered}
\sin ^{2}(\xi)=\frac{(1-\cos (2 \xi))}{2} \\
\sin (\zeta) \cos (\chi)=\frac{\sin (\zeta+\chi)+\sin (\zeta-\chi)}{2}
\end{gathered}
$$

The switch RMS current $\mathrm{I}_{\mathrm{q}, \mathrm{RMS}}$ is given by,

$$
\mathrm{I}_{\mathrm{q}, \mathrm{RMS}}=\left(\frac{\hat{\mathrm{I}}_{\mathrm{sa} 1}^{2}}{8 \pi}\left(\pi+\frac{8}{3} \mathrm{M} \cos (\theta)\right)\right)^{\frac{1}{2}}
$$

The values of the switch RMS current calculated by (10) and obtained from simulation are shown in Fig. 4 for different power factors. Table 1 shows the parameters of the system under concern. These data are obtained from [7], to allow direct comparison between the results from analytical expressions derived here with those given in [7] from simulation and test-rig.

\section{TABLE I}

PARAMETERS OF THE SYSTEM UNDER CONCERN

\begin{tabular}{|l|l|}
\hline Full load power & $7.5 \mathrm{hp}$ \\
\hline Per-phase rated current & $20.1 \mathrm{~A}$ \\
\hline Per-phase rated voltage & $220 \mathrm{~V}$ \\
\hline Frequency & $60 \mathrm{~Hz}$ \\
\hline
\end{tabular}

A good corroboration between the simulated and calculated results is shown in Fig. 4. Moreover, the results in Fig. 4 are nearly identical to those in Fig. 8-b in [7]. 


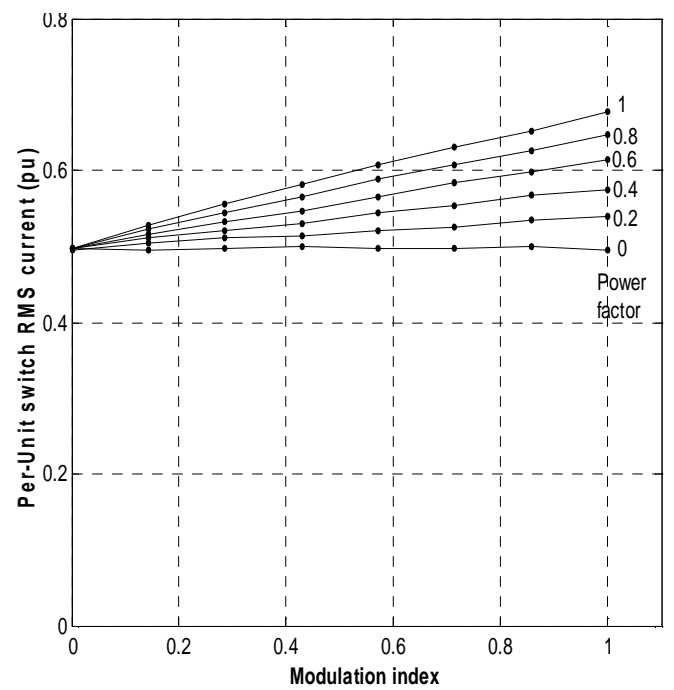

(a) Calculated results

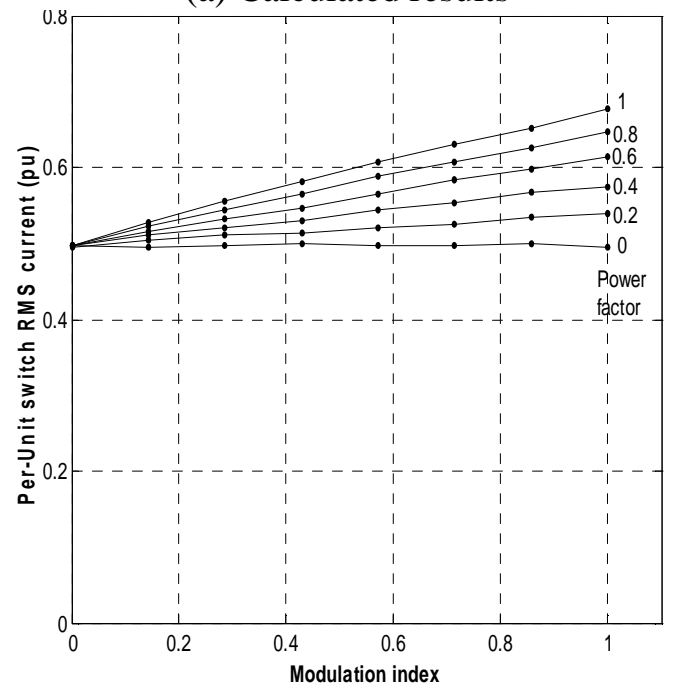

(b) Simulated results

Fig. 4 Per-unit RMS switch current versus modulation index for different values of power factor (a) Calculated by (10) (b) Simulated

The diode RMS current can be calculated following the same procedures used for switch RMS current; however, switch duty cycle should be replaced by diode counterpart. Fortunately diode duty ratio is related to that of the switch [10].

$$
d^{\prime}(t)=1-d(t)=\frac{1-M \sin (\omega t)}{2}
$$

In a similar fashion, diode RMS current $\mathrm{I}_{\mathrm{d}, \mathrm{RMS}}$ is given by,

$$
\mathrm{I}_{\mathrm{d}, \mathrm{RMS}}=\left(\frac{\hat{\mathrm{I}}_{\mathrm{sal}}^{2}}{8 \pi}\left(\pi-\frac{8}{3} \mathrm{M} \cos (\theta)\right)\right)^{\frac{1}{2}}
$$

The values of the diode RMS current calculated by (12) and obtained from simulation are shown in Fig. 5 for different power factors. 
Again a good correlation between the simulated and calculated results is shown in Fig.5. The results in Fig.5 are approximately similar to those in Fig.8-c in [7].

"Reference [7]" established factor $\mathrm{k}$ as the product of the power factor $\cos (\theta)$ and modulation index $\mathrm{M}$, and predicated that $\mathrm{k}$ has significant influence on the RMS and average currents. However, the relation between the RMS and average currents and $\mathrm{k}$ was inaccurate in [7]. For example, equation (21) in [7] states that the RMS switch (transistor) current is linear function in $\mathrm{k}$. This approximation introduced significant errors in calculating the RMS currents as shown in Figs. 11-b and 11-d in [7]. The cause of the error could not be explained in [7]. Equations (10) and (12) here in this paper show in a simple way the nonlinear relationship between RMS currents and $\mathrm{k}$, which explains the mysterious of [7].

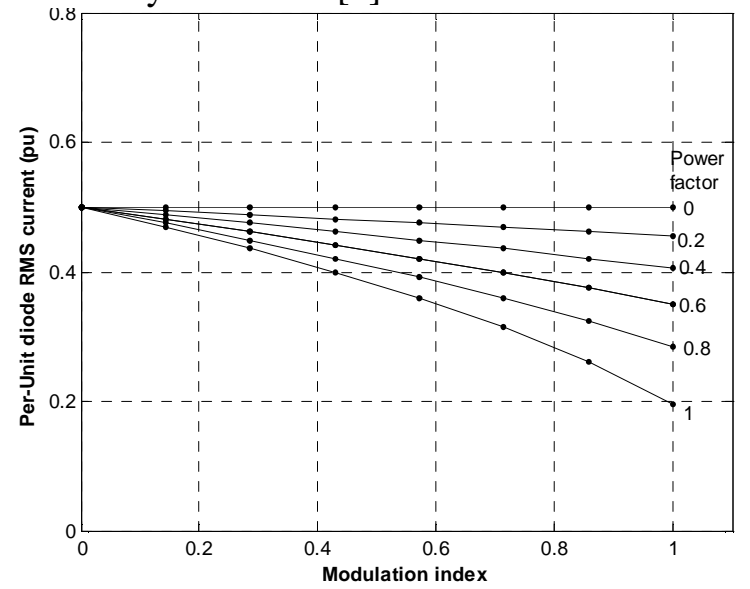

(a) Calculated results

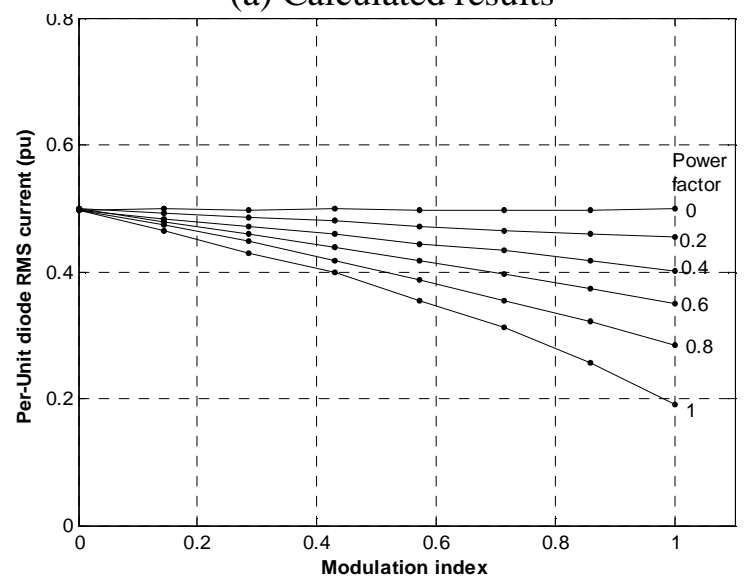

(b) Simulated results

Fig. 5 Per-unit RMS diode current versus modulation index for different values of power factor (a) Calculated by (12) (b) Simulated

2) Average currents: A switch or a diode average current can be computed by,

$$
\mathrm{I}_{\mathrm{i}, \mathrm{av}}=\left(\frac{1}{\mathrm{~T}_{\mathrm{i}}} \int_{0}^{\mathrm{T}_{\mathrm{i}}} \mathrm{i}_{\mathrm{i}} \mathrm{dt}\right)
$$

$\mathrm{i}$ is either $\mathrm{q}$ or $\mathrm{d}$ 
Following the same procedure as in Section 4.a, the switch and diode average currents are given by,

$$
\begin{aligned}
\mathrm{I}_{\mathrm{q}, \mathrm{av}} & =\frac{\hat{\mathrm{I}}_{\mathrm{sal}}}{2 \pi}\left(1+\frac{\pi}{4} \operatorname{Mcos}(\theta)\right) \\
\mathrm{I}_{\mathrm{d}, \mathrm{av}} & =\frac{\hat{\mathrm{I}}_{\mathrm{sal}}}{2 \pi}\left(1-\frac{\pi}{4} \operatorname{Mcos}(\theta)\right)
\end{aligned}
$$

Equations (14)-(15) show obviously the linear relationship between the factor $\mathrm{k}$ and the average currents. Although the linear relationship between $\mathrm{k}$ and the average currents was predicted in [7]; however, the feature of this relationship was not recognized.

The average currents calculated by (14) and (15) and obtained from simulations are shown in Fig. 6 and Fig. 7 respectively.

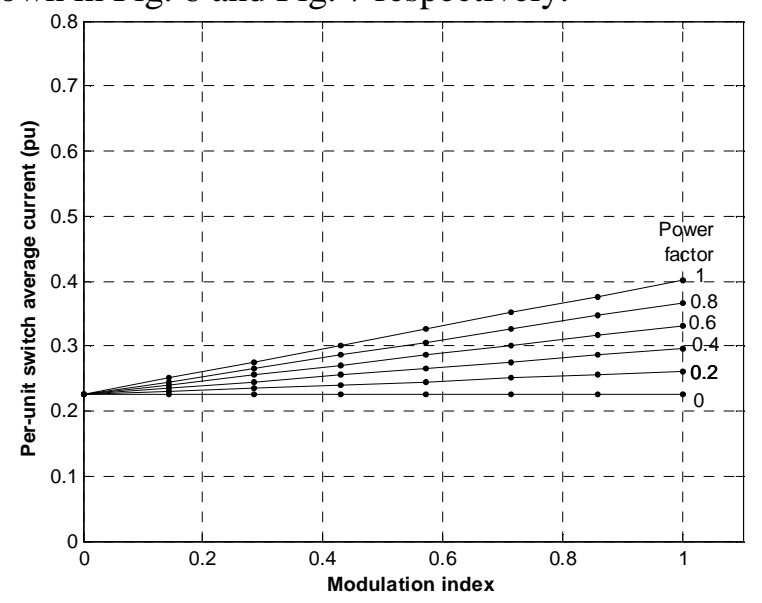

(a) Calculated results

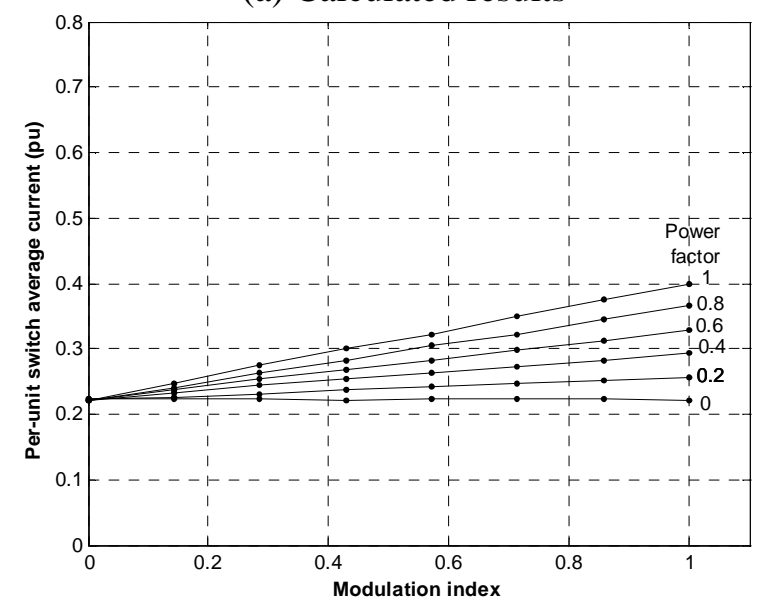

(b) Simulated results

Fig. 6 Per-unit average switch current versus modulation index for different values of power factor (a) Calculated by (14) (b) Simulated

A good correlation is shown between the simulated and calculated results in Fig. 6. Moreover, Fig. 6 is approximately identical to Fig. 8-a in [7]. 


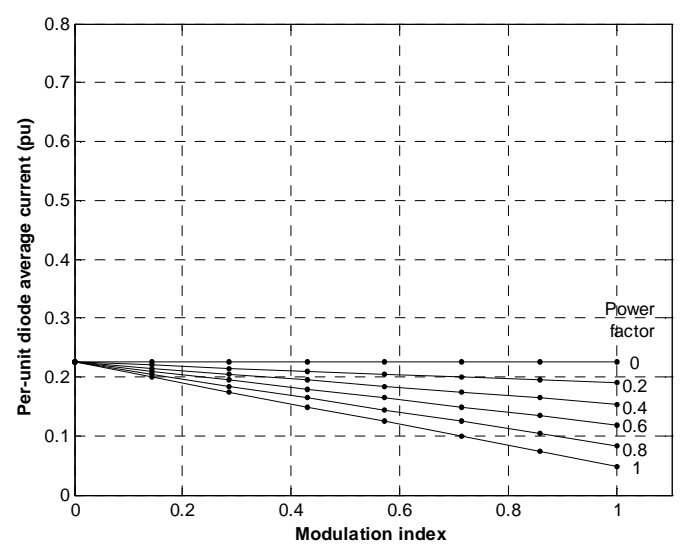

(a) Calculated results

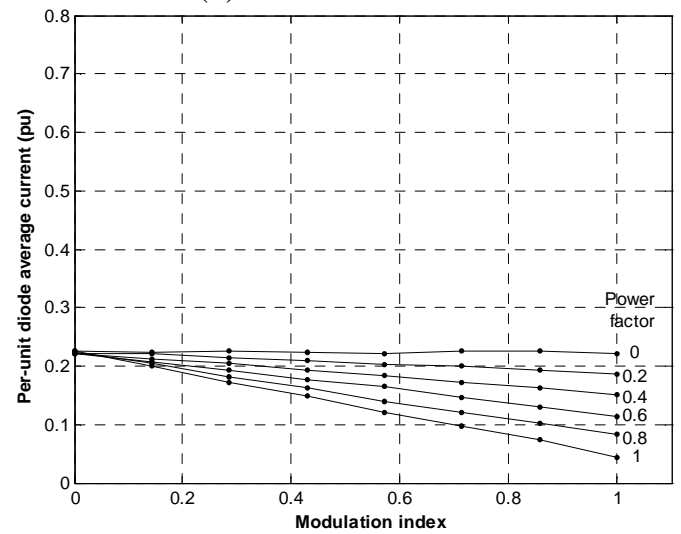

(b) Simulated results

Fig. 7 Per-unit average diode current versus modulation index for different values of power factor (a) Calculated by (15) (b) Simulated

A good correspondence is shown between Fig.7 and Fig.8-c in [7].

3) Peak currents: The peak values of the switch and diode currents are computed by,

$$
\begin{gathered}
\mathrm{I}_{\text {q,peak }}=\hat{\mathrm{I}}_{\mathrm{sa}} \\
\mathrm{I}_{\text {d,peak }}=\hat{\mathrm{I}}_{\text {sa1 }}
\end{gathered}
$$

\section{3- SIX-STEP OPERATION}

In medium-high power application, the inverter operation is principally drafted from PWM into square mode. This is to reduce/eliminate switching losses and hence boosting the efficiency. The inverter output voltage for square wave operation is given by,

$$
\mathrm{v}_{\mathrm{an}}(\mathrm{t})=\sum_{\mathrm{n}=1,5,7}^{\infty} \frac{4 \mathrm{~V}_{\mathrm{DC}}}{3 \mathrm{n} \pi}\left(1+\cos \left(\frac{\mathrm{n} \pi}{3}\right)\right) \sin (\mathrm{n} \omega \mathrm{t})
$$

The harmonics in the voltage of square wave inverter occurs at $j 6 \pm 1,(18)$, where $j=1,2,3$. Two cases are investigated here: 
A. When the square wave inverter is attached directly to the line (filter-less operation).

B. An appropriate AC-line filter is incorporated with square wave inverter; therefore the AC-line current is approximately sinusoidal.

\section{1-Six-step, filter-less operation}

1) RMS currents: When the inverter operates without filter in the output side, the output current is given by,

$$
\mathrm{i}_{\mathrm{sa}}=\hat{\mathrm{I}}_{\mathrm{sa} 1} \sin (\omega \mathrm{t}-\theta)+\sum_{\mathrm{n}=5,7, . .}^{\infty} \hat{\mathrm{I}}_{\mathrm{san}} \sin \left(\mathrm{n} \omega \mathrm{t}-\frac{\pi}{2}\right)
$$

Where the current amplitude $\hat{\mathrm{I}}_{\mathrm{san}}$ at $\mathrm{n}$ harmonic is related to DC-link voltage $\mathrm{V}_{\mathrm{DC}}$, sub-transient load $\mathrm{L}_{\mathrm{S}}^{\prime \prime}$ inductance by,

$$
\hat{\mathrm{I}}_{\text {san }}=\frac{4 \mathrm{~V}_{\mathrm{DC}}}{3 \mathrm{n}^{2} \pi \omega \mathrm{L}_{\mathrm{s}}^{\prime \prime}}\left(1+\cos \left(\frac{\mathrm{n} \pi}{3}\right)\right)
$$

Low order harmonics contributed significantly in the inverter output input current, which increases the size and the cost of the added filter. The square of the switch RMS current could be computed by,

$$
\mathrm{I}_{\mathrm{q}, \mathrm{RMS}}^{2}=\frac{1}{2 \pi} \int_{\beta}^{\pi} \mathrm{i}_{\mathrm{q}}^{2} \mathrm{~d} \omega \mathrm{t}
$$

The integration limits in (21) are from $\beta$ to $\pi$, which are the boundaries of the switch conduction period in the six-step mode. $\beta$ is the angle, where the switch starts to conduct. It could be calculated by equating (19) to zero and replacing $\omega$ t by $\beta$.

$$
\mathrm{i}_{\mathrm{sa}}=\hat{\mathrm{I}}_{\mathrm{sa} 1} \sin (\beta-\theta)+\sum_{\mathrm{n}=5,7, . .}^{\infty} \hat{\mathrm{I}}_{\mathrm{san}} \sin \left(\mathrm{n} \beta-\frac{\pi}{2}\right)=0
$$

Equation (22) could be solved using numerical techniques such as Newton Raphson. Substituting (19) into (21), simplifying and integrating, the square of the switch RMS current is given by,

$$
\begin{aligned}
& \mathrm{I}_{\mathrm{q}, \mathrm{RMS}}^{2}=\frac{\hat{\mathrm{I}}_{\mathrm{sa} 1}^{2}}{4 \pi}\left[(\pi-\beta)+\frac{1}{2}(\sin 2(\theta)+\sin 2(\beta-\theta))\right]+\sum_{\mathrm{n}=5,7}^{\infty} \frac{\hat{\mathrm{I}}_{\mathrm{san}}^{2}}{4 \pi}\left[(\pi-\beta)-\frac{1}{2 \mathrm{n}} \sin (2 \mathrm{n} \beta)\right] \\
& +\sum_{\mathrm{n}=5,7}^{\infty} \frac{\hat{\mathrm{I}}_{\mathrm{san}} \hat{\mathrm{I}}_{\mathrm{sa} 1}}{2 \pi(\mathrm{n}+1)}[-\cos ((\mathrm{n}+1) \beta-\theta)+\cos (\theta)]-\sum_{\mathrm{n}=5,7}^{\infty} \frac{\hat{\mathrm{I}}_{\mathrm{san}} \hat{\mathrm{I}}_{\mathrm{sa} 1}}{2 \pi(\mathrm{n}-1)}[\cos ((\mathrm{n}-1) \beta+\theta)-\cos (\theta)]
\end{aligned}
$$

The RMS values of the switch current calculated by (23) and obtained from the simulation are illustrated in Fig. 8.

Figure 8 shows good correlation between the calculated and simulated results. The diode in the switch-diode pair conducts from 0 to $\beta$. The square of the diode RMS current is obtained by,

$$
\mathrm{I}_{\mathrm{d}, \mathrm{RMS}}^{2}=\frac{1}{2 \pi} \int_{0}^{\beta} \mathrm{i}_{\mathrm{d}}^{2} \mathrm{~d} \omega \mathrm{t}
$$




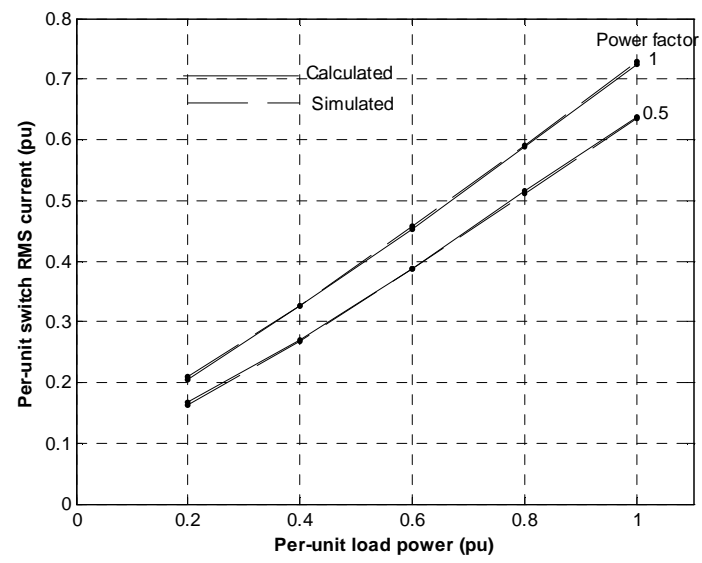

Fig. 8: Per-unit RMS switch current versus load power, (solid) calculated by (23), and (dashed) simulated.

Substituting (19) into (24), simplifying and integrating the square of diode RMS current is

$$
\begin{aligned}
& \mathrm{I}_{\mathrm{d}, \mathrm{RMS}}^{2}=\frac{\hat{\mathrm{I}}_{\mathrm{sa} 1}^{2}}{4 \pi}\left[\beta-\frac{1}{2}(\sin 2(\theta)+\sin 2(\beta-\theta))\right]+\sum_{\mathrm{n}=5,7}^{\infty} \frac{\hat{\mathrm{I}}_{\mathrm{san}}^{2}}{4 \pi}\left[\beta+\frac{1}{2 \mathrm{n}} \sin (2 \mathrm{n} \beta)\right] \\
& +\sum_{\mathrm{n}=5,7}^{\infty} \frac{\hat{\mathrm{I}}_{\mathrm{san}} \hat{\mathrm{I}}_{\mathrm{sa}}}{2 \pi(\mathrm{n}+1)}[\cos ((\mathrm{n}+1) \beta-\theta)+\cos (\theta)]-\sum_{\mathrm{n}=5,7}^{\infty} \frac{\hat{\mathrm{I}}_{\mathrm{san}} \hat{\mathrm{I}}_{\mathrm{sa1}}}{2 \pi(\mathrm{n}-1)}[-\cos ((\mathrm{n}-1) \beta+\theta)-\cos (\theta)]
\end{aligned}
$$

The RMS values of the diode current obtained from detailed simulation and calculated by (25) are given in Fig. 9.

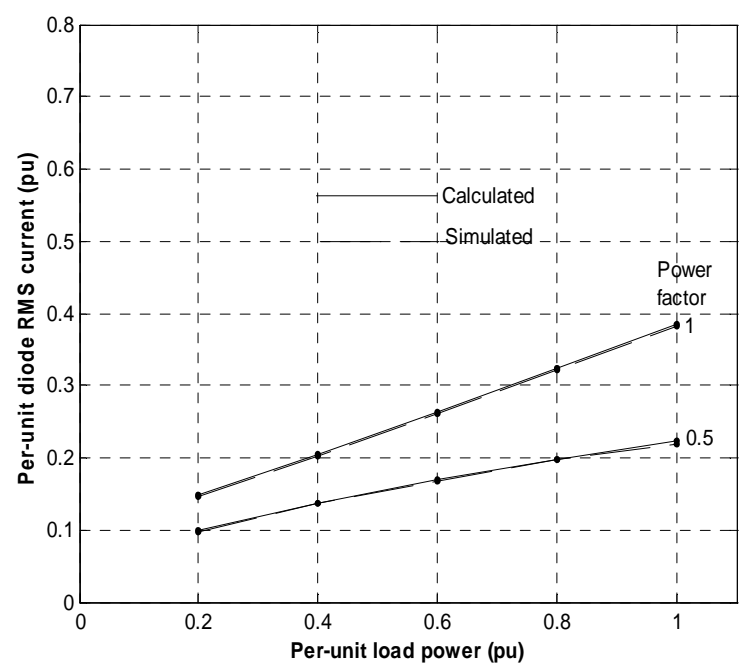

Fig. 9: Per-unit RMS diode current versus load power, (solid) calculated by (25), and (dashed) simulated

In general, there is a good agreement between the analytical and simulated results in Fig. 9. The switches carry more current than the diodes particular at high power factors, Figs. 8-9.

2) Average currents: The switch average current could be calculated by, 


$$
I_{q, a v}=\frac{1}{2 \pi} \int_{\pi}^{\beta} i_{s a} d \omega t
$$

Substituting (19) into (26), the switch average current is given by,

$$
\mathrm{I}_{\mathrm{q}, \mathrm{av}}=\frac{\hat{\mathrm{I}}_{\mathrm{sal}}}{2 \pi}(\cos (\beta-\theta)+\cos (\theta))+\sum_{n=5,7 . .}^{\infty} \frac{\hat{\mathrm{I}}_{\mathrm{san}}}{2 \mathrm{n} \pi}(\sin (\mathrm{n} \beta))
$$

The diode average current could be computed by,

$$
I_{d, a v}=\frac{1}{2 \pi} \int_{0}^{\beta} i_{d} d \omega t
$$

Substituting (19) into (28), the diode average current is given by,

$$
I_{d, a v}=\frac{\hat{I}_{\text {sa1 }}}{2 \pi}(\cos (\beta-\theta)-\cos (\theta))+\sum_{n=5,7 . .}^{\infty} \frac{\hat{\mathrm{I}}_{\mathrm{san}}}{2 \mathrm{n} \pi} \sin (\mathrm{n} \beta)
$$

The average switch and diode currents calculated by (27) and (29) and obtained from the simulation are shown in Figs.10-11 respectively.

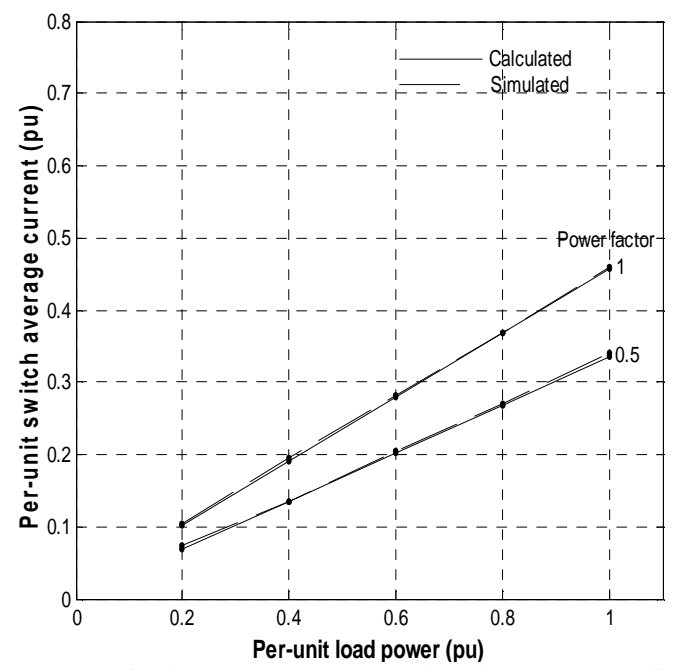

Fig. 10 Per-unit average switch current versus load power,(solid) calculated by (27), and (dashed) simulated

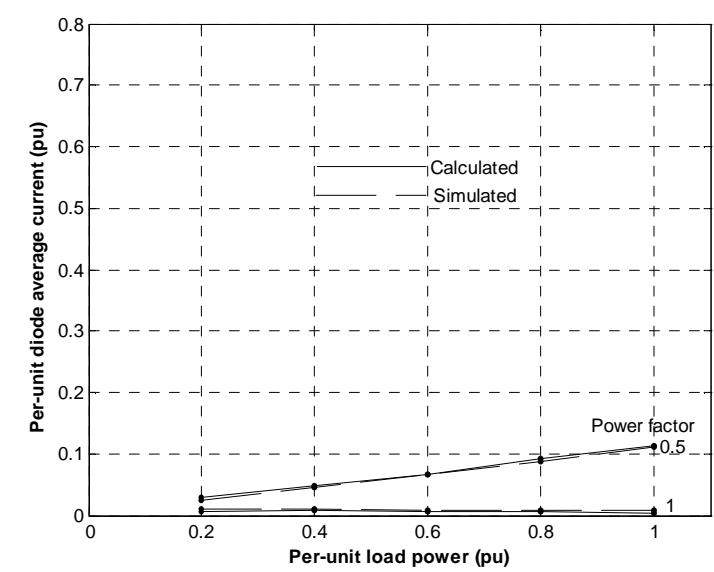

Fig. 11 Per-unit average diode current versus load power,(solid) calculated by (29), and (dashed) simulated 
The anaytical results correboates with the simulated ones, Figs. 10-11. In prodcuing Figs. 8-11, only the fifth and seventh harmonics are considered in equations (23), (25), (27) and (29) and in the simulation.

Comparing Fig. 6 and Fig. 10 shows that the switches carries more currents in sixstep mode than in PWM. This may be attributed to the harmonics in case of square wave mode.

\section{2-Six-step operation with filter}

An efficient filter [1,5-6] is generally required, in case of the inverter operation in sixstep mode. This is to remove/reduce the unwanted harmonics and comply with harmonic standards [2,3]. Under these considerations, the inverter output voltage would be likely sinusoidal and the harmonic components in the inverter output current equation (19) are to be set to zero.

For the inverter operation in square wave with output side filter the conduction periods of the switches and diodes are different from the case in Section III. A-1. For example, the switch conducts from $\theta$ to $\pi$, while the diode conducts from 0 to $\theta$.

1) RMS currents: The switch and diode RMS currents following the same procedure as in Section III. A-1 are given respectively by,

$$
\begin{aligned}
\mathrm{I}_{\mathrm{q}, \mathrm{RMS}} & =\left[\frac{\hat{\mathrm{I}}_{\text {sal }}^{2}}{4 \pi}\left[(\pi-\theta)+\frac{1}{2}(\sin 2(\theta))\right]\right]^{\frac{1}{2}} \\
\mathrm{I}_{\mathrm{d}, \mathrm{RMS}} & =\left[\frac{\hat{\mathrm{I}}_{\text {sal }}^{2}}{4 \pi}\left[\theta-\frac{1}{2}(\sin 2(\theta))\right]\right]^{\frac{1}{2}}
\end{aligned}
$$

The expressions of the switch and diode RMS currents given in (30)-(31) are identical to those given in [10] for single-phase rectifier. However, in [10] the expressions for switch RMS and diode currents respectively have $-/+$ signs before $\sin (2 \theta)$ term, which is opposite to (30)-(31). This is attributed to the reversal direction of current from rectification mode in [10] to inversion mode here.

The values of the switch RMS current calculated by (30) and obtained from simulation are shown in Fig. 12 for different power factors.

Again a good correlation is shown between the simulated and analytical results in Fig. 11. The RMS current increases with the power factor, which is attributed to the increase of the transistor conduction period.

The values of the diode RMS current calculated by (31) and obtained from simulation are shown in Fig. 13 for different power factors. 


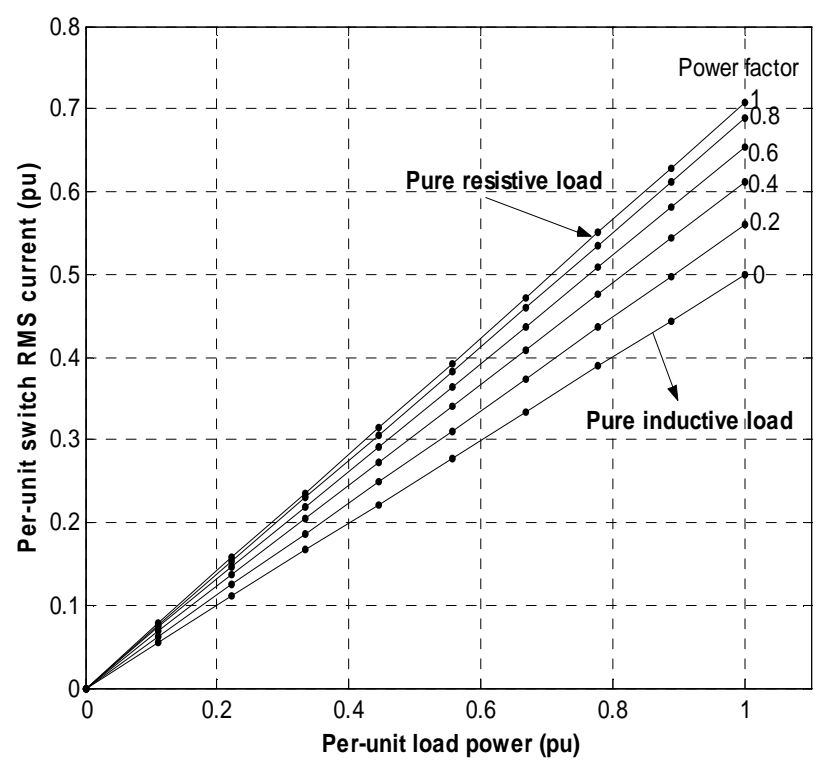

(a) Calculated results

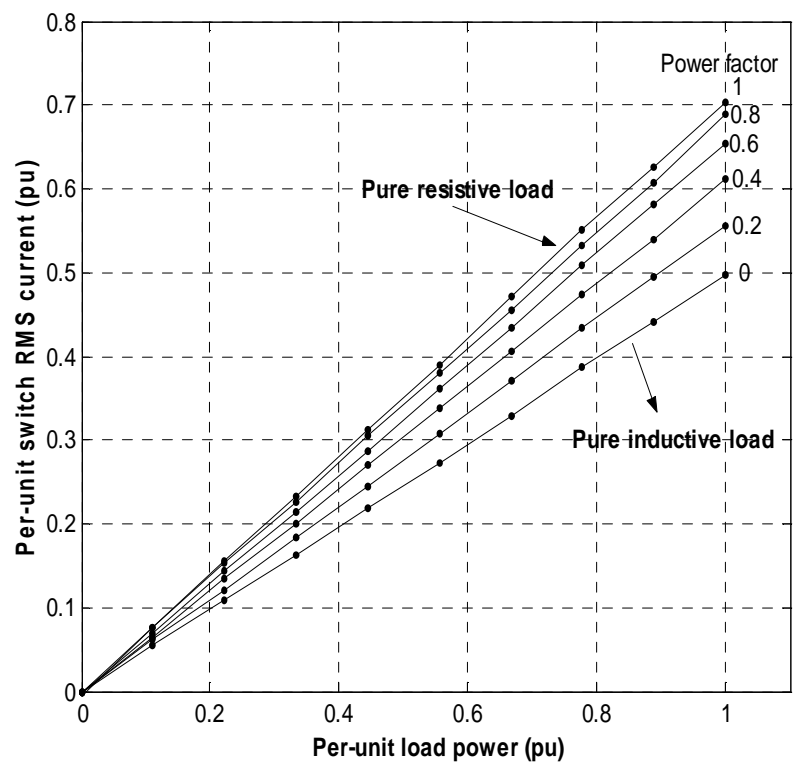

(b) Simulated results

Fig.12 Per-unit RMS transistor current versus modulation index for different values of power factor (a) Calculated by (30) (b) Simulated 


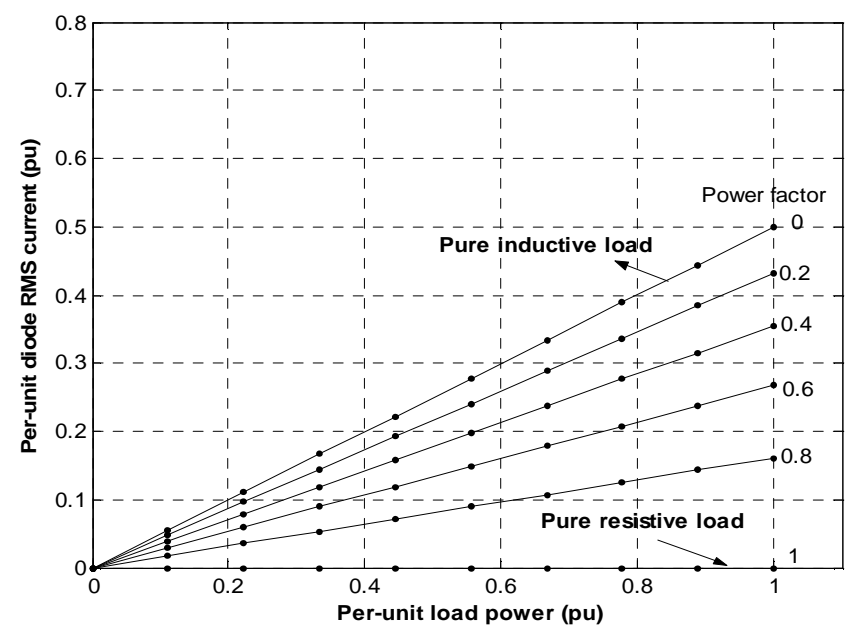

(a) Calculated results

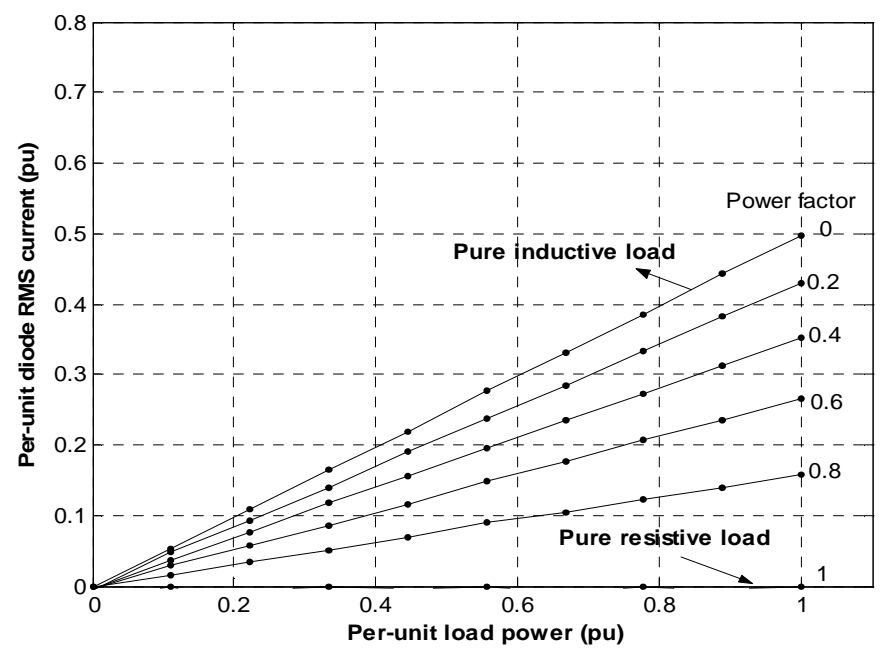

(b) Simulated results

Fig.13 Per-unit RMS diode current versus modulation index for different values of power factor (a) Calculated by (31) (b) Simulated

Figure 12 indicates that for unit power factor operation the current is mainly carried by the switch; the diode conduction angle increases as the power factor decreases, until it reaches the maximum value of $\pi / 4$ at zero power factor.

Comparing Figs. 10-11 with Figs. 12-13 shows that adding input filter to the square wave inverter has the advantage of reducing solid-state currents.

2) Average currents: The average values of the switch and diode currents obtained following the same procedure in 5.b.1 are given by,

$$
\begin{aligned}
& \mathrm{I}_{\mathrm{q}, \mathrm{av}}=\frac{1}{2 \pi}\left[\hat{\mathrm{I}}_{\mathrm{sa} 1}(1+\cos (\theta))\right] \\
& \mathrm{I}_{\mathrm{d}, \mathrm{av}}=\frac{1}{2 \pi}\left[\hat{\mathrm{I}}_{\mathrm{sa} 1}(1-\cos (\theta))\right]
\end{aligned}
$$


Equations (32) and (33) indicate that as the load power factor improves the conduction period of the diode decreases until it diminishes for unity power factor operation. Equations (32) and (33) show obviously the relation between the semiconductors average currents and the power they handle.

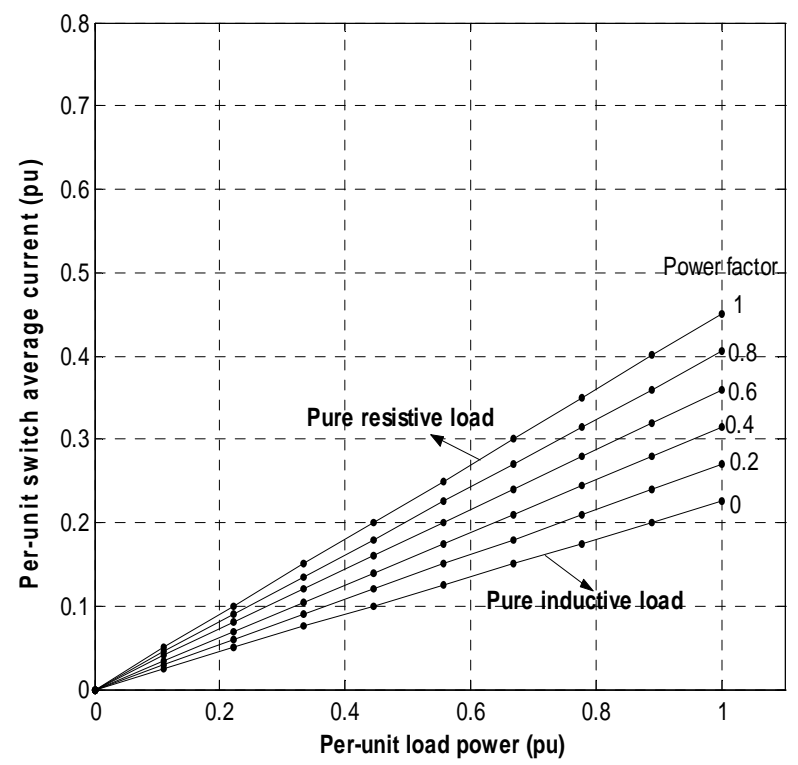

(a) Calculated results

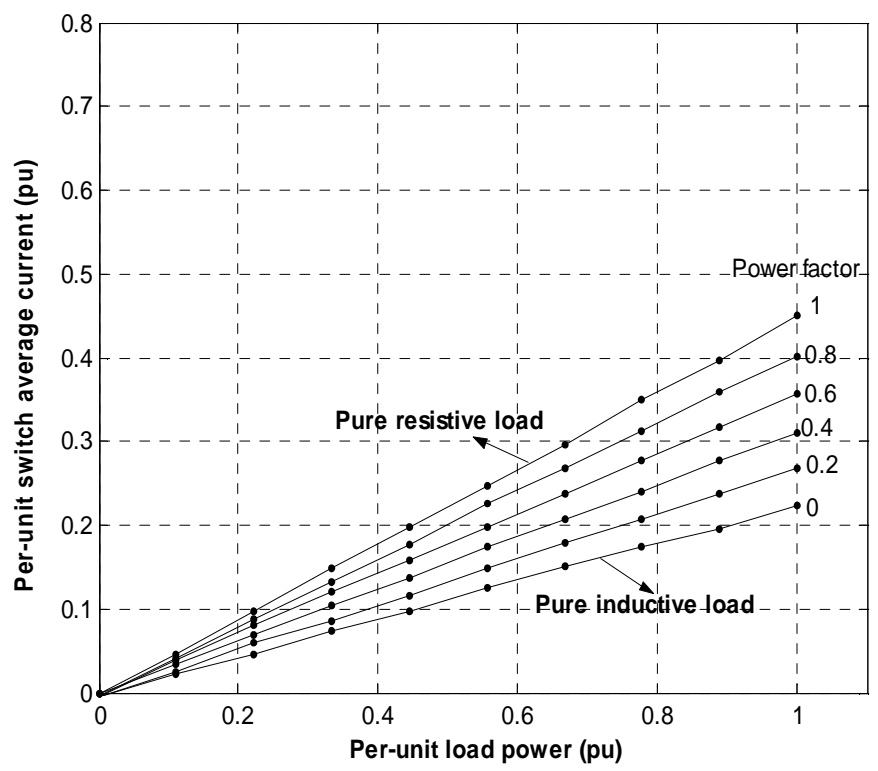

(b) Simulated results

Fig. 14 Per-unit Average transistor current versus modulation index for different values of power factor (a) Calculated by (32) (b) Simulated

The values of the switch and diode average currents calculated by (30) and (31) and obtained from simulation are shown in Figs. (14) and (15) respectively. 


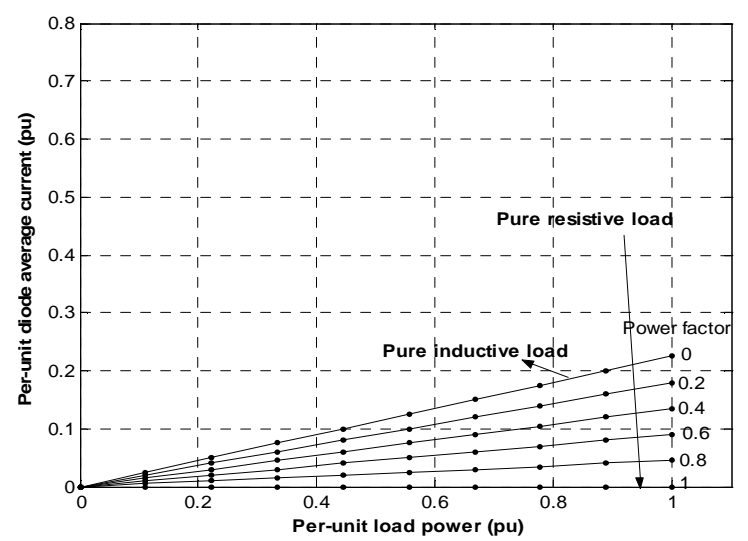

(a) Calculated results

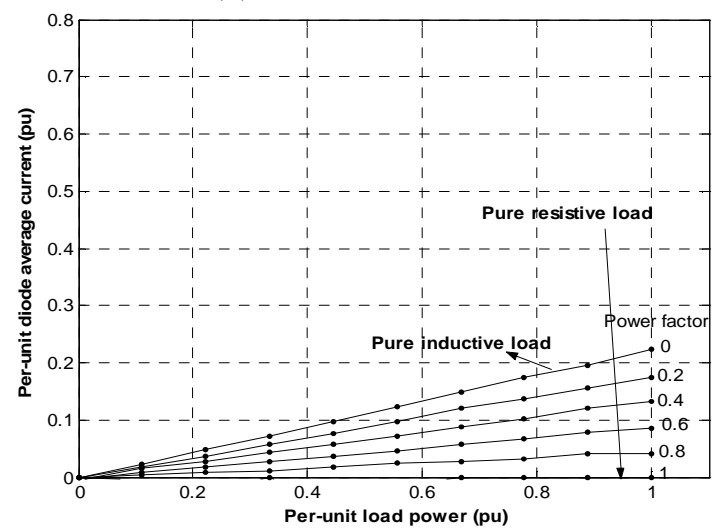

(b) Simulated results

Fig. 15 Per-unit Average diode current versus modulation index for different values of power factor (a) Calculated by (33) (b) Simulated

3) Peak currents: The peak values of the switch and the diode currents for the inverter operation in six-step mode with a filter could be calculated by,

$$
\begin{gathered}
\mathrm{I}_{\text {q,peak }}=\hat{\mathrm{I}}_{\text {sa1 }} \\
\mathrm{I}_{\text {d,peak }}=\hat{\mathrm{I}}_{\text {sal }} \sin (\theta)
\end{gathered}
$$

\section{4- CONCLUSION}

The following conclusions are drawn:

1. The RMS and average currents of the switches and diodes in three-phase inverter usually are determined by computer aided methods. These methods are usually unreliable, time consuming and inefficient.

2. In "ref. [7]" the RMS and average currents were computed by sophisticated numerical technique; however significant errors were produced.

3. Novel and robust analytical expressions are proposed for calculating the RMS, average and peak currents of three-phase inverter. These expressions are applicable 
to different operating conditions. Moreover, they address the inverter operation in six-step mode with/without any added filter.

4. The graphs show good correlation between the analytical currents expressions and simulation results.

5. The proposed expressions highlight the factors that affect RMS, peak and average currents in a simple and clear manner.

6. The proposed expressions solved the mysterious in [7]. A sustained DC component in the phase current results from a short circuit failure of one of the switching elements of the H-bridge attached to this phase.

\section{5- REFERENCES}

[1] Martinez, R.; Enjeti, P.N.”A high-performance single-phase rectifier with input power factor correction" IEEE transition on Power Electronics, vol. 11, pp. 311317, March 1996.

[2] Industrial A.C Networks Affected by Harmonics-Application of Filters and Shunt Capacitors, IEC 61642, 1997

[3] Department of defence interface standard, USA" MIL-STD-704E" Aircraft Electrical Power Characterises, pp. 1-33, 1 may 1999.

[4] J. W. Kolar and S. D. Round, "Analytical calculation of the RMS current stress on the DC-link capacitor of voltage-PWM converter systems," Electric Power Applications, IEE proceedings vol. 153, pp. 533-540,.2006.

[5] Mohan, N.; Undeland, T., M., William P. Robbins "Power electronics: converters, applications and design" 2nd edition, Chichester ,Wiley, England 1995

[6] Robert W., Erickson; Dragan, Maksimovic "Fundamentals of Power Electronics" $2^{\text {nd }}$ edition, Springer, USA, 2001

[7] Thurston, R.C.; Legowski, S.F.;"A simple and accurate method of computing average and RMS currents in a three-phase PWM inverter" IEEE Transaction on Power Electronics, vol. 8, pp. 192-199, 1993.

[8] S. Legowski, R. Thurston, and A. M. Trzynadlowski, "Intemal combustion and electric drive system for a land vehicle," Res. Rep. Univ. Wyoming Grant 5/37896, June 1990.

[9] P. D. Ziogas, E. P. Wiechmann, and V. R. StefanoviC, "A computer aided analysis and design approach for static voltage source inverters," IEEE Transaction Industrial Application., vol. IA-21,pp. 1234-1241, Oct. 1985.

[10] A.AbdElhafez, F. N. Abed El-bar" RMS, DC and Peak currents of PWM and square-ware rectifiers" 13th International Middle East Power System Conference 2009, MEPCON 2009,pp. 545-550, 20-23 December ,2009.

\section{اجراء بسيط لتصميم مغير ثُلاثي الاوجه على القدرة}

يقدم هذا البحث صيغ رياضية لتيارات القيمة الفعالة، العظمي و المتوسطة في المغير ثلاثي الاوجة الذي يعمل تحت ظروف تشغيل مختلفة ـ النتائج تم التاكد منها عن طريقة المحاكاة . 